\title{
Emotional adjustment of children and adolescents with haemophilia in relation to the HIV threat
}

\author{
M. G. C. BOSWERGER, K. FIJNVANDRAAT, A. M. H. VAN VELDHUIZEN, F. R. ROSENDAAL and \\ M. PETERS \\ Department of Paediatric Haematology and Paediatric Psychosocial Department, Academic Medical Center, University of \\ Amsterdam, Emma Children's Hospital AMC; Haemostasis and Trombosis Research Centre, University Hospital Leiden, the \\ Netherlands
}

Summary. A Dutch nation-wide study on young haemophilia patients, whose former treatment placed them at risk for HIV infection, was done to examine the effect of HIV testing, HIV status, disclosure of HIV status and the child's experiences with disease-related information on emotional adjustment. In the Netherlands HIV tests are not routinely performed for paediatric haemophilia patients, but the number of HIV-infected children is estimated to be low $(8 \%)$. Seventy-two boys with haemophilia, five HIV positive, $51 \mathrm{HIV}$ negative and 16 not tested, and their mothers were interviewed and administered standardized questionnaires. Multiple regression analyses showed no differences in anxiety and depression between HIV-positive, HIV-negative or untested boys, nor between children who were informed or not informed about their HIV status. Conversely, children who experienced more difficulties to obtain information about the their disease were significantly more anxious and tended to be more depressed. No significant differences in emotional distress were found between the patients and a standardization sample of healthy peers. The data provide evidence that children and adolescents with haemophilia cope effectively with their disease and the emotional impact of the HIV threat. There seems to be no reason to protect children from testing or knowing their HIV status. In the absence of compelling medical reasons, however, health care workers should not forcefully advocate testing or early disclosure. Distinct disease and treatment-related factors as well as social factors modify disclosure practices.

Keywords: adolescents, children, disclosure, emotional adjustment, haemophilia, HIV.
Around 1984 it was discovered that haemophiliacs were at risk for AIDS, owing to transfusion with HIV-infected blood and blood clotting factor concenctrates [1]. Although transmission of HIV via this route has now been virtually eliminated through effective donor screening and heat treatment of blood products [2, 3], individuals with haemophilia treated before 1985 were at significant risk. Since the HIV test became available in 1985, the difficult decision of whether to test for HIV has had to be taken by haemophiliacs and by parents of haemophiliac children. Additionally, parents had to decide whether to inform their child about the HIV status. Fortunately, the numbers of children infected with HIV in the Netherlands are estimated to be low. Patients with AIDS are registered in this country, seropositives are

Correspondence: Marjolein Peters, MD, Academic Medical Center, University of Amsterdam, Emma Children's Hospital AMC, Department of Paediatric Haematology, PO Box 22700, 1100 DE Amsterdam, the Netherlands. Tel: 31-20-5662727, fax: 31-206917735.

Received 13 December 1995; accepted 18 June 1996 not. The most recent registration figures (June 1994) reveal that 29 children (0-13 years) have AIDS. [4] This number accounts for $0.9 \%$ of all AIDS patients. Only two of the 29 children were haemophilia patients. The number of HIV-infected haemophilia patients is undoubtedly higher. A quite reliable estimate is based on a nationwide survey among all Dutch haemophiliacs conducted in $1992[5,6]$. Of all patients who have been exposed to untested blood products, $79 \%$ of the children and $75 \%$ of the adults were tested for HIV; $8 \%$ of the tested children and $11 \%$ of the tested adults were reported to be seropositive.

The literature indicates that children with various chronic diseases are somewhat more likely to show psychological adjustment problems than healthy children, although the majority cope effectively with the disease and the demands of treatment [7], Before the HIV crisis, adjustment problems of paediatric haemophiliacs hardly received attention [8]. For obvious reasons, the emotional impact of having haemophilia was deemed to be much stronger after the HIV crises. Initial studies assessing the 
psychological adaptation of paediatric haemophilia patients to the HIV crises did not report the HIV status of their samples and produced mixed results. One study [9], for example, found high levels of self-reported depression in the majority of the children and adolescents with haemophilia, while in another study [10] adolescents with haemophilia had levels of self-reported anxiety and depression comparable with that of normative reference groups. Recently, a number of studies compared the psychological adjustment of HIV-positive and HIVnegative children and adolescents with haemophilia. With a few exceptions these studies found no differences between these groups in self-reported anxiety and depression [11, 12], in social anxiety, social adaptation and adjustment to haemophilia [12], in patient and parent ratings of intrafamilial stress [13] and in parent and teacher ratings of behavioural problems and psychiatric disturbance $[11,14]$. Furthermore, on all these psychological dimensions the HIV-infected and uninfected patients did not differ from standardization samples, healthy control groups or other chronic disease groups such as asthma and diabetes. The exceptions were found in the well-controlled study of Drotar et al. [12], in which the $\mathrm{HIV}$-positive group reported less positive effects and more repressive defensiveness than the HIV-negative group, and in Bussing \& Burket's study [13], in which the HIVpositive patients had more anxiety disorders than the HIV-negative patients, the control groups of healthy children and children with asthma. In the last study, the HIV-negative patients, in contrast, demonstrated less anxiety disorders than the asthma group, and both the HIV-positive and the HIV-negative groups showed less intrafamilial stress than the asthma patients.

The inconsistent findings concerning the psychological impact of HIV infection on children and adolescents with haemophilia are usually assumed to reflect the influence of divergent methods as well as methodological problems, e.g. small sample sizes. With the exception of Drotar et al.'s large study, they have also been conducted at single sites and as such are unlikely to be representative of a broader population of children and adolescents with haemophilia.

Finally, the topic of disclosure of the HIV or AIDS diagnosis to the child has received attention in the clinical literature [15, 16]. Lipson [15] considers the question of whether the 'model of paediatric oncology' is applicable to HIV and AIDS. In this model research shows that children with cancer benefit from early disclosure of the diagnosis [17, 18]. HIV and AIDS, however, are distinguished from other chronic or fatal illness by special cultural and social conditions, including suffering from other losses by the family, and the stigma associated with parent-to-child transmission, drug use and sexual conduct. These factors complicate the communication process [15, 16], and, although these factors are not associated with the route of HIV infection in haemophilia, these patients may still fall victim to discrimination. Some reports of clinical experience suggest that disclosure of the diagnosis under the proper circumstances is beneficial for children with HIV/AIDS [15, 16]. Some recent studies among haemophilia patients report that all seropositive patients were informed of their HIV status [12, 13]. To our knowledge there is only one study that has investigated the effect of different disclosure practices in seropositive children with haemophilia. In this study, by Logan et al. [11], a small group of seropositive children who were informed of their HIV status by their parents $(n=4)$ were compared with seropositive children who were not informed of their HIV status $(n=5)$. Knowledge of HIV status did not appear to be related to the children's psychiatric disturbance or depression.

The present study was designed to determine the emotional adjustment in a group of children and adolescents with haemophilia, treated in all haemophilia centres in the Netherlands, and whose former treatment exposed them to the risk of HIV infection and AIDS. The first aim of the study was to determine the prevalence of anxiety and depression in three groups of patients: an HIV-positive group, an HIV-negative group and a group not tested for HIV. The second aim of the present study was to investigate whether psychological distress is related to the information of their HIV status the children received from their parents. The children's sources of information about the disease, their information obstacles and information needs were also assessed.

\section{Materials and methods}

\section{Subjects and procedure}

Seventy-two haemophiliac boys and their mothers participated in the study. Inclusion criteria for the children were: age between 8 and 18 years and a history of treatment with clotting factors concentrates before 1985 . When families had more than one haemophiliac child, only one child was randomly chosen to participate.

After approval from the Institutional Review Board, all 103 eligible patients from all Dutch academic and nonacademic haemophilia centres and their parents were asked to participate. Informed consent was obtained from the parents and adolescents, and assent was obtained from the younger children. A total of 72 boys with haemophilia and their mothers agreed to participate (response rate $70 \%$ ). Five boys were HIV positive, 51 HIV negative and 16 not tested. None of the HIV positive boys had been diagnosed as having AIDS. The seronegative and untested children who participated in the study had no HIV-positive brothers and the HIV-positive

(C) Blackwell Science Ltd 
subjects were the only child with haemophilia in the family. Children and their mothers were interviewed each individually at the family home. The interviews were carried out by two interviewers (M.B. and K.F.) in 1992 and 1993.

\section{Medical data}

Data concerning severity of haemophilia, treatment history before 1985, HIV testing, HIV status and diagnosis of AIDS were obtained from the haemophilia treatment centres with parental permission. The severe form of haemophilia has been defined as plasma factor VIII or IX concentration being less than $1 \%$ and the mild/moderate form between 1 and $25 \%$.

\section{Instruments}

Interview. A standardized interview was developed both for the children and for their mothers. For this part of the study the relevant topics included: (i) for the children, experiences with haemophilia and treatment, and knowledge of the former existence of the HIV risk; (ii) for the mothers, biographical data, specific details about HIV testing, its result and information about the test result given to the child by the parents.

Questionnaires. Emotional adjustment of the child was measured by self-report questionnaires and maternal ratings. Standardized psychological self-report measures consisted of the Dutch version of Spielberger's 20-item Trait Anxiety Inventory for Children (STAIC-trait) with a score range of 20-80 [19, 20], and the Dutch Depression Questionnaire For Children [21]. This questionnaire has 88 items, an overall depression scale (score range 0-88) and several subscales of which the following three were used: negative self-esteem (score range 0-15), negative appraisal of social environment (score range 0-7) and negative expectations for the future (score range 0-7). Finally, the Information Questionnaire for Chronically Ill Children was administered [17]. This questionnaire has nine items subdivided into the following three subscales: first, sources of information, measuring the availability of (persons who are willing to give) information about the disease (score range $0-5$ ); secondly, information obstacles, measuring problems the child experiences when trying to obtain information about the disease (score range $0-2$ ); and third, information needs, measuring the child's need to be informed about the disease (score range 0-2). Maternal ratings of the child's anxiety and depression were acquired, using two subscales of the Behavioural Assessment Scale [17]. This scale has bipolar items. The depression subscale has eight items (score range 8-56). The anxiety subscale has three items (score range 3-21).

(C) Blackwell Science Ltd
All instruments have proven to be reliable and valid and have been used in our previous studies in chronically ill children [17].

\section{Statistical analysis}

The effect of nine independent predictor variables (Table 1) on the dependent variables anxiety and depression was examined using hierarchical multiple regression analysis using SAS version 6.03. This technique selects the independent variables which best explain the variance in the dependent variables. Five independent variables are dichotomous: HIV testing $(0=$ not tested, $1=$ tested $)$, HIV status $(0=\mathrm{HIV}$ negative/not tested, $1=\mathrm{HIV}$ positive), information about HIV status given to the child $(0=$ not informed, 1 =informed), knowledge of the former existence of the HIV risk $(0=$ unknown, $1=$ known $)$ and severity of haemophilia $(0=\mathrm{mild} /$ moderate, $1=$ severe $)$. Four variables are continuous, i.e. sources of information, information obstacles, information needs about the disease and age of the child. The effect of an independent variable was considered to be significant when it contributes to the variance at $P<0.05$ and suggestive for an effect when $0.05>P<0.10$. Furthermore, Pearson correlations were used to examine the interrelationships between the independent variables, and between maternal ratings and children's ratings. Mean anxiety and depression scores of the haemophilic children were compared with those of Dutch standardization groups of healthy peers of similar age and sex [20-22] using Student $t$-tests.

Table 1. The independent predictor variables used in the regression analyses.

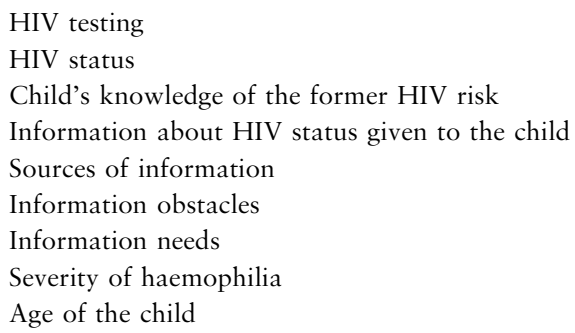

\section{Results}

Patient characteristics. The proportion of patients with a severe or mild/moderate type of haemophilia was approximately the same in the two different age groups (Table 2). The decision to test for HIV or refrain from testing rested with the parents $(81 \%)$ or with the parents and the child (17\%). In two cases $(3 \%)$ the doctor performed an HIV test without consulting the parents and/or patients. Afterwards the parents were asked whether they wanted to know the test result, and after 
Table 2. Characteristics of the haemophilia patients in the total sample and in the two different age groups.

\begin{tabular}{lccc}
\hline & $\begin{array}{l}\text { Total sample } \\
8-18 \text { years } \\
(n=72)\end{array}$ & $\begin{array}{l}\text { Children } \\
8-12 \text { years } \\
(n=30)\end{array}$ & $\begin{array}{c}\text { Adolescents } \\
13-18 \text { years } \\
(n=42)\end{array}$ \\
\hline $\begin{array}{l}\text { Severity of haemophilia } \\
\text { severe }\end{array}$ & $35(49)^{*}$ & $13(43)$ & $22(52)$ \\
mild/moderate & $37(51)$ & $17(57)$ & $20(48)$ \\
HIV status of the child & & & \\
HIV-positive & $5(7)$ & $0(0)$ & $5(12)$ \\
HIV-negative & $51(71)$ & $22(73)$ & $8(69)$ \\
Untested & $16(22)$ & $8(27)$ & $31(74)$ \\
Child's knowledge of HIV risk & & & $7(17)$ \\
HIV risk known (tested) & $40(56)$ & $9(30)$ & $3(7)$ \\
HIV risk known (untested) & $10(14)$ & $3(10)$ & $1(2)$ \\
HIV risk unknown (tested) & $16(22)$ & $5(17)$ & $32(76)$ \\
HIV risk unknown (untested) & $6(8)$ & & $2(5)$ \\
Information about HIV status given to the child & & $16(53)$ & $8(19)$ \\
informed (tested) & $48(67)$ & $6(20)$ & $8(27)$ \\
not informed (tested) & $8(11)$ & & \\
not informed (untested) & $16(22)$ & & \\
\hline
\end{tabular}

"No. $(\%)$.

consenting they were told their child was seronegative. In all 12 cases $(17 \%)$ in which the child had been involved in the decision-making process, HIV tests were only performed when consensus between parents and patients was reached. Reasons not to involve children in decisionmaking were, according to the mothers, that the child was thought to be too young $(53 / 60,88 \%)$ and/or that it would elicit unnecessary fears in the child $(25 / 60,42 \%)$. The mothers of the 16 untested patients $(16 / 72,22 \%)$ explained their decision not to allow testing by the slight chance of HIV infection $(9 / 16,56 \%)$, by not wanting to have knowledge of the child's HIV status as long as there is no hope for cure $(5 / 16,31 \%)$ or by the child not wanting to have knowledge of the HIV status as long as there is no hope for cure $(2 / 16,13 \%)$. All five HIVpositive patients had the severe type of haemophilia and were all in the oldest age group. Each demonstrated their knowledge of the former HIV risk as did 35 of the 51 HIVnegative and 10 of the 16 untested children and adolescents. All HIV-positive patients showed awareness of their HIV status. They were informed by their parents 1-5 years after the HIV test was performed (6-42 months before the interview took place). The reason given for the delay in disclosing the HIV status was that the parents needed time to recover from the shock themselves and wanted to protect their child from fears aroused by knowledge of a fatal prognosis. Eventually, the child was told the diagnosis because the parents felt the child had the right to know $(n=3)$ or because the HIV symptoms and its treatment asked for an explanation $(n=2)$. Sixteen per cent $(8 / 51)$ of the children whose HIV test result was negative were not informed about it because the parents did not want to confront the child with the painful topic of AIDS and/or were afraid of undermining the child's faith in the haemophilia treatment.

Interrelations between predictor variables. The following significant correlations were found. Children who demonstrated knowledge of the former HIV risk were older $(r=+0.52)$, had been more often informed about their HIV status by their parents $(r=+0.37)$, reported to have more sources of information about their disease $(r=+0.37)$ and reported to experience fewer information obstacles $(r=-0.24)$, in comparison with children who did not demonstrate knowlege of the former HIV risk. Moreover, a significant negative correlation between age and information obstacles $(r=-0.31)$ was found, indicating that younger children thought they had more problems obtaining information about their disease. Finally, it was found that information sources were inversely related to information obstacles $(r=-0.30)$.

Anxiety reported by the child. Of all included predictor variables, only information obstacles showed a significant regression coefficient, indicating that children experiencing more difficulties obtaining information about their disease were more anxious (Table 3). None of the other factors significantly contributed to anxiety.

Depression reported by the child. Age was found to be the only factor having a significant relationship with depression, indicating that younger children with haemophilia 
Table 3. Results of multiple regression analyses. Independent variables predicting anxiety and depression (sub)scale scores of the children and adolescents.

\begin{tabular}{lllll}
\hline & $\beta$ & $95 \%$ confidence interval & $R^{2}$ & $P$ \\
\hline Anxiety score & & & 0.19 & 0.0002 \\
$\quad$ Information obstacles & +3.58 & +1.80 to +5.36 & & \\
Depression total score & & & 0.12 & 0.004 \\
$\quad$ Age & -1.06 & -1.76 to -0.36 & 0.04 & 0.08 \\
$\quad$ Sources of information & -2.59 & -5.41 to +0.23 & 0.11 & 0.005 \\
$\begin{array}{l}\text { Negative self-esteem* } \\
\quad \text { Age }\end{array}$ & -0.22 & -0.37 to -0.07 & & \\
$\begin{array}{l}\text { Negative appraisal of } \\
\text { social environment* } \\
\text { Age }\end{array}$ & -0.11 & -0.20 to -0.02 & 0.07 & 0.03 \\
\hline "Depression subscale score. & & &
\end{tabular}

were more depressed, had a lower self-esteem and had a more negative appraisal of their social environment (Table 3). The other variables did not significantly contribute to overall depression or other dimensions of depression. There was, however, a tendency that children who felt they had a greater availability of information sources were less depressed.

Maternal ratings of the child's anxiety and depression. None of the predictor variables had any significant relationship with the mothers' ratings of the child's anxiety and depression. The correlations between the maternal ratings and the children's ratings of anxiety and depression ranged from $r=0.00$ to $r=0.10$.

Comparisons of mean scores within the sample and with standardization samples. Table 4 presents the mean scores of the dependent variables according to HIV status. There were no significant differences in the mean scores on any of the anxiety and depression measures between the three patient groups. Comparison of the mean scores of the two different age groups with age-matched standardization groups of healthy peers did also not reveal any differences in anxiety or depression. All the mean scores of the patients were within one standard deviation of the standardization samples.

\section{Discussion}

This nation-wide study on young patients from all haemophilia treatment centres in the Netherlands sought to assess the emotional adjustment of children and adolescents whose former treatment placed them at risk for HIV infection. In the past decade, parents of children with haemophilia had to decide whether their child should be tested for HIV. In the Dutch haemophilia centres such tests are not routinely performed. Intensive counselling by physicians, in which arguments against and in favour of testing are carefully considered, usually precedes decisionmaking. According to the parents in this study, the ultimate decision almost always rested with them. In the study $22 \%$ of the children and adolescents had still not

Table 4. Mean scores (SD) on the anxiety and depression (sub)scales of the children, and the maternal ratings of anxiety and depression in the child, according to HIV status.

\begin{tabular}{|c|c|c|c|}
\hline & $\begin{array}{l}\text { HIV-positive } \\
(n=5)\end{array}$ & $\begin{array}{l}\text { HIV-negative } \\
(n=51)\end{array}$ & $\begin{array}{l}\text { Untested } \\
(n=16)\end{array}$ \\
\hline \multicolumn{4}{|l|}{ Self-report scales } \\
\hline Anxiety scale & $28.80(4.97)$ & $30.67(6.11)$ & $30.31(5.16)$ \\
\hline $\begin{array}{l}\text { Depression total } \\
\text { scale }\end{array}$ & $13.80(7.53)$ & $15.96(9.54)$ & $16.81(11.99)$ \\
\hline $\begin{array}{l}\text { Negative self- } \\
\text { esteem* }\end{array}$ & $1.40(1.14)$ & $2.42(2.06)$ & $2.25(2.08)$ \\
\hline $\begin{array}{l}\text { Negative appraisal } \\
\text { of social environment* }\end{array}$ & $0.80(0.45)$ & $1.16(1.27)$ & $0.94(1.39)$ \\
\hline $\begin{array}{l}\text { Negative expectations } \\
\text { for the future* }\end{array}$ & $2.20(2.28)$ & $1.30(1.07)$ & $1.50(1.21)$ \\
\hline \multicolumn{4}{|l|}{ Maternal ratings } \\
\hline Anxiety & $11.60(2.70)$ & $9.59(3.87)$ & $9.69(3.74)$ \\
\hline Depression & $29.40(8.56)$ & $24.53(7.66)$ & $24.81(7.88)$ \\
\hline
\end{tabular}

"Depression subscale score. 
been tested, and $7 \%$ of the tested children were seropositive. These figures correspond closely with the data of a recent Dutch nation-wide survey among children and adults with haemophilia, in which the figures for children in the same age groups were $21 \%$ and $8 \%$, respectively $[5,6]$. Although there may be a slight underreporting, HIV seroprevalence is considered to be relatively low in the Netherlands, and this low risk was often used by parents as an argument to refuse HIV testing. In other cases the parents and/or patients preferred to be kept in the dark as long as there is no effective treatment for AIDS. Relatively few children had been involved in the decision-making process concerning HIV testing. Most parents wanted to protect the child from the stress and fear of discussing this painful topic.

In the present study no difference in emotional distress could be found between HIV-positive (without symptoms of AIDS), HIV-negative and untested patients. These groups did not differ from each other in self-reported anxiety, depression, self-esteem, appraisal of social environment or expectations for the future, nor did they differ from healthy peers. The maternal ratings of the child's anxiety and depression also revealed no differences between the groups. Given the small number of HIVpositive subjects in our sample, significant differences may be difficult to demonstrate. However, our findings are consistent with a number of other studies and also with Drotar et al.'s recent study [12], in which the anxiety and depression of a large group of seropositive children and adolescents of the same age as in our study were comparable with those of the seronegative children and adolescents.

Age appeared to be a more important factor in explaining emotional distress than HIV status. The younger children with haemophilia were more depressed, had a lower self-esteem and were more critical of the persons around them than the older children. This finding should, however, be interpreted with caution. The effect of the age variable is significant but small, and similar age differences also occur in healthy subjects [19-22]. The quite favourable psychological adjustment of patients in the present study may be due to selection bias. The $70 \%$ response rate may indicate that the patients are a selfselected group. It is possible that families who chose to participate may have included children with better psychological adjustment than those who declined participation. It is also possible that the sources of medical and psychological support for patients and families, provided by the specialized haemophilia centres, and by the wellorganized national patient organization, favourably affected the patients' adaptation.

It has often been suggested that children with a chronic and/or serious illness use a coping style of 'positive denial' [12, 23-26]. Striking examples of such a coping style were

Haemophilia (1997), 3, 39-45 demonstrated by the HIV-positive subjects in this study. Almost all of them said in the interview they had no worries about developing AIDS, and were confident that drugs to prevent or cure AIDS would be found in time. For quite a few HIV-negative and untested subjects in the study $(14 / 67,21 \%)$, in contrast, it seems that the HIV threat is still there. They indicated they were not sure their current treatment was safe and expressed worries about a possible HIV infection in the future. It might explain why differences in HIV status did not appear to affect children's emotional adjustment in this study.

Another main question of the study relates to the effect of disease-related information in general and information on HIV status in particular. The results are somewhat conflicting. On the one hand, we found that patients for whom it is difficult to get information about their disease were significantly more anxious and tended to be more depressed than patients not experiencing such difficulties. A similar result has been obtained in our previous study on children with cancer [17]. On the other hand, no evidence could be found that giving or withholding information about the HIV status affected the child's emotional adjustment. For the seronegative children it seems common sense to think that they would be better off knowing this than being kept in the dark. The majority of the tested and untested patients were aware of the former HIV risk. Nevertheless, quite a number of children whose HIV test was negative were not given this seemingly reassuring information by their parents. All HIV-positive children, in contrast, were told the diagnosis, even though 1-5 years after testing. In both groups parents wanted to protect the child from the painful emotions associated with the knowledge of having been a potential or being a real victim of the disease.

Until now little is known about disclosing HIV/AIDS to children. Some reports of clinical experience suggest that disclosure under the proper circumstances is beneficial for children with HIV/AIDS [15, 16]. Our data support this clinical experience, but at the same time we have no indications that the delay in disclosure was detrimental to the patients. It suggests that the oncology model, which stresses the importance of early disclosure $[15,17,18]$, is of limited relevance for HIV-infected children. Several distinguishing disease-related and social factors may explain why early disclosure is of more importance for children with cancer than for HIV-infected children with haemophilia.

In conclusion, these data provide additional evidence that children with haemophilia cope effectively with the emotional impact of the HIV threat. Seropositive, seronegative and untested haemophilia patients functioned equally well, and showed no distress symptoms. On the basis of our findings it could also be concluded that there is no reason to protect haemophiliac children

(C) Blackwell Science Ltd 
from HIV testing or from knowing their HIV status. In the absence of compelling medical reasons, however, it seems good medical practice that health-care professionals do not forcefully advocate HIV testing or early disclosure of the HIV diagnosis to the child. Our study suggests that disclosure models, which have been shown to be valid in oncology, are not uniformly applicable to other types of chronic or fatal diseases. More research is needed to examine whether our findings and advise on disclosure have relevance for other families affected by HIV/AIDS, but they are consistent with clinical findings and recommendations described by Lipson and Tasker [15, 16]. At least one extrapolation from our study seems to be valid for other chronic or fatal diseases. Children's adjustment is less favourable when they experience difficulties obtaining information about the illness. This highlights the importance of recognizing children's informational needs, and the need to support families in using adaptive styles of coping with sensitive information.

\section{Acknowledgements}

This study was supported by grants from the Praeventiefonds and the Stichting Haemophilia. We thank M. Prins for his statistical advice and A. H. M. Triemstra, H. M. van der Ploeg and E. Briët for their cooperation. We are grateful to all patients and their parents who were prepared to participate in the study and to the Dutch Haemophilia Treatment Centres for their collaboration.

\section{References}

1 Centers for disease control. Update: acquired immuno deficiency syndrome (AIDS) in persons with haemophilia. MMWR, 1984; 33: 589.

2 Dietrich SL. The epidemiology of HIV infection in hemophiliacs. In: Kasper C, ed. Recent Advances in Haemophilia Care. New York: Alan R. Liss, 1990: 79-87.

3 Eyster ME. Natural history and transmission of hemophiliaassociated Human Immunodeficiency Virus (HIV) infections. In: Hilgartner MW, Pochedly C, eds. Hemophilia in the Child and Adult. New York: Raven, 1989: 263-74.

4 Geneeskundige Hoofdinspectie van de Volksgezondheid (GHI). Gegevens van de Geneeskundige Hoofdinspectie van de Volksgezondheid. Rijswijk: GHI, 1994.

5 Triemstra AHM, Van der Ploeg HM, Smit C, Briët E, Rosendaal FR. Hemofilie in Nederland 4: verslag van een landelijk onderzoek in 1992 onder mensen met hemofilie. Amsterdam/Leiden: Werkgroep Hemofilie in Nederland 4, 1994.

6 Triemstra AHM, Smit C, Van der Ploeg HM, Briët E, Rosendaal FR. Two decades of haemophilia treatment in the Netherlands, 1972-92. Haemophilia 1995; 1: 165-71.

7 Eiser C. Psychological effects of chronic disease. J Child Psychol Psychiat 1990; 31: 85-98.

8 Bussing R, Johnson SB. Psychosocial issues in hemophilia before and after the HIV crises: a review of current research. Gen Hosp Psychiat 1992; 14: 387-403.

9 Burton KR, Hill SM, Bright CI, Kemph JP, Mehta P. Symptoms of depression in pediatric hemophiliac patients. Pediatr Res 1989; 25(12A): 58.

10 Overby KJ, Lo B, Litt IF. Knowledge and concerns about Acquired Immunodeficiency Syndrome and their relationship to behavior among adolescents with hemophilia. Pediatrics 1989; 83: 204-10.

11 Logan FA, Maclean A, Howie CA, Gibson B, Hann IM, Parry-Jones WL. Psychological disturbance in children with haemophilia. BMJ 1990; 301: 1253-6.

12 Drotar DD, Agle DP, Eckl CL, Thompson PA. Psychological response to HIV Positivity in Hemophilia. Pediatrics 1995; 96: 1062-8.

13 Bussing R, Burket RC. Anxiety and intrafamilial stress in children with hemophilia after the HIV crisis. J Am Acad Child Adolesc Psychiatry 1993; 32: 562-7.

14 Hooper SR, Whitt JK, Tennison M, Burchinal M, Gold S, Hall C. Behavioral adaptation to human immunodeficiency virus-seropositive status in children and adolescents with hemophilia. Am J Dis Child 1993; 147: 541-5.

15 Lipson M. Disclosure of diagnosis to children with human immunodeficiency virus or acquired immunodeficiency syndrome. J Dev Behav Pediatr 1994; 15 (Suppl. 3): S61-5.

16 Tasker M. How Can I Tell You? Bethesda, MD: Association for the Care of Children's Health, 1992.

17 Van Veldhuizen AM, Last BF. Children with Cancer: Communication and Emotions. Amsterdam/Lisse, the Netherlands: Swets \& Zeitlinger, 1991.

18 Spinetta JJ, Maloney LJ. The child with cancer: patterns of communication and denial. J Consult Clin Psychol 1978; 46: 1540-1.

19 Spielberger CD, Edwards CD, Lushene RE, Montuori J, Platzek D. STAIC Preliminary Manual for the State-Trait Anxiety-Inventory for Children. Palo Alto, CA: Consulting Psychologists Press, 1973.

20 Bakker FC, Van Wieringen PC, Van der Ploeg HM, Spielberger CD. Handleiding bij de Zelf-BeoordelingsVragenlijst voor Kinderen ZBV-K. Liss, the Netherlands: Swets \& Zeitlinger, 1989.

21 De Wit CAM. Depressie bij kinderen, psychologische theorie en operationalisering. Leuven: Acco, 1985.

22 Grootenhuis MA. Hoe beoordelen ouders gevoelens van angst en depressie bij hun kind? Internal report, Universiy of Amsterdam, Faculty of Psychology, June 1994.

23 Brown LK, Schultz JR, Gragg RA. HIV-infected adolescents with hemophilia: adaptation and coping. Pediatrics 1995; 96: 459-63.

24 Worchel FF, Nolan BF, Wilson VL, Purser JS, Copeland DR, Pfefferbaum B. Assessment of depression in children with cancer. J Pediatr Psychol 1988; 13: 101-12.

25 Kellerman J, Zeltzer L, Ellenberg L, Dash J, Rigler D. Psychological effects of illness in adolescence: I. anxiety, selfesteem, and perception of control. J Pediatr 1980; 97: 126-31.

26 Nannis ED, Susman EJ, Strope BE, et al. Correlates of control in pediatric cancer patients and their families. $J$ Pediatr Psychol 1982; 7: 75-84. 